Hope College

Hope College Digital Commons

Faculty Publications

6-1-2008

\title{
The Development of Day-night Differences in Sleep and Wakefulness in Norway Rats and the Effect of Bilateral Enucleation
}

\author{
Andrew J. Gall \\ University of lowa, gall@hope.edu \\ William D. Todd \\ University of lowa \\ Baisali Ray \\ University of lowa \\ Cassandra M. Coleman \\ University of lowa \\ Mark S. Blumberg \\ University of lowa \\ Follow this and additional works at: https://digitalcommons.hope.edu/faculty_publications \\ Part of the Behavioral Neurobiology Commons, and the Biological Psychology Commons
}

\section{Recommended Citation}

Repository citation: Gall, Andrew J.; Todd, William D.; Ray, Baisali; Coleman, Cassandra M.; and Blumberg, Mark S., "The Development of Day-night Differences in Sleep and Wakefulness in Norway Rats and the Effect of Bilateral Enucleation" (2008). Faculty Publications. Paper 1504.

https://digitalcommons.hope.edu/faculty_publications/1504

Published in: Journal of Biological Rhythms, Volume 23, Issue 3, June 1, 2008, pages 232-241. Copyright (c) 2008 SAGE.

This Article is brought to you for free and open access by Hope College Digital Commons. It has been accepted for inclusion in Faculty Publications by an authorized administrator of Hope College Digital Commons. For more information, please contact digitalcommons@hope.edu. 


\title{
The Development of Day-Night Differences in Sleep and Wakefulness in Norway Rats and the Effect of Bilateral Enucleation
}

Andrew J. Gall, William D. Todd, Baisali Ray, Cassandra M. Coleman, and Mark S. Blumberg Program in Behavioral and Cognitive Neuroscience, Department of Psychology, University of lowa, lowa City, IA, 52242, USA

\begin{abstract}
The suprachiasmatic nucleus (SCN) exhibits circadian rhythmicity in fetal and infant rats, but little is known about the consequences of this rhythmicity for infant behavior. Here, in Experiment 1, we measured sleep and wakefulness in rats during the day and night in postnatal day (P)2, P8, P15 and P21 subjects. As early as P2, day-night differences in sleep-wake activity were detected. Nocturnal wakefulness began to emerge around P15 and was reliably expressed by P21. We hypothesized that the process of photic entrainment over the first postnatal week, which depends upon the development of connectivity between the retinohypothalamic tract (RHT) and the SCN, influences the later emergence of nocturnal wakefulness. To test this hypothesis, in Experiment 2 infant rats were enucleated bilaterally at P3 and P11, that is, before and after photic entrainment. Whereas pups enucleated at P11 and tested at P21 exhibited increased wakefulness at night, identical to sham controls, pups enucleated at P3 and tested at P21 exhibited the opposite pattern of increased wakefulness during the day. Pups tested at P28 and P35 exhibited this same pattern of increased daytime wakefulness. All together, these results suggest that prenatal and postnatal experience modulates the development of species-typical circadian sleep-wake patterns. Moreover, we suggest that visual system stimulation, via the RHT's connections with the SCN, exerts an organizational influence on the developing circadian system and, consequently, contributes to the emergence of nocturnality in this species.
\end{abstract}

\section{Keywords}

circadian rhythm; nocturnal; diurnal; EMG; development; retinohypothalamic tract; suprachiasmatic nucleus

\footnotetext{
The circadian system in mammals is regulated in part by an internal "clock" located within the suprachiasmatic nucleus (SCN) of the hypothalamus (Moore 1983, Rusak and Zucker 1979). Endogenous SCN rhythms are first detected prenatally in rats (Reppert et al. 1988). During the early postnatal period in rats, physiological (e.g., metabolic rate) and behavioral (e.g., suckling) circadian rhythms are present (Ellison et al. 1972, Henning and Gisel 1980, Kittrell and Satinoff 1986, Nuesslein-Hildesheim et al. 1995, Spiers 1988). However, in comparison to the vast literature on the circadian rhythms of sleep and wakefulness in adults (Fuller et al. 2006), very little is known about such rhythms in infants.
}

Corresponding author: Mark S. Blumberg, Department of Psychology, University of Iowa, Iowa City, IA, 52242, USA, e-mail: E-mail: mark-blumberg@uiowa.edu, Phone: 319.335.2424, Fax: 319.335.0191. 
On the basis of electroencephalographic (EEG) measures of sleep, it has been reported that nocturnal wakefulness is expressed by postnatal day 20 (P20) in rats (Frank and Heller 1997). Because EEG activity cannot be used to provide reliable measures of sleep and wakefulness before P10 (Gramsbergen 1976), we have relied upon electromyographic (EMG) measures instead (Karlsson and Blumberg 2005). Accordingly, here we use nuchal EMG to assess the development of sleep and wakefulness during the day and night at P2, P8, P15, and $\mathrm{P} 21$. We find that the nuchal EMG is sufficiently sensitive to detect day-night differences in sleep-wake activity soon after birth, as well as the emergence of nocturnal wakefulness around P15.

In early infancy — before P8 in rats — the dam entrains her pups' circadian rhythms. Thereafter, light becomes the predominant entraining stimulus (Duncan et al. 1986, Ohta et al. 2002, Takahashi and Deguchi 1983). This transition from maternal to photic entrainment has been attributed to the development of the retinohypothalamic tract (RHT). Even at birth in rats, melanopsin-containing retinal ganglion cells are directly responsive to light and form functional connections with the SCN via the RHT (Hannibal and Fahrenkrug 2004, Sekaran et al. 2005). The strength of connectivity between the RHT and SCN increases over the first postnatal week and becomes adult-like by the end of the second postnatal week (Hannibal and Fahrenkrug 2004, Speh and Moore 1993).

Here, in Experiment 2, we examined the role of visual system stimulation on the later emergence of nocturnal wakefulness by enucleating infant rats at P3 and P11, that is, before and after photic entrainment, respectively. Pups enucleated at P3 were tested at P8, P15, P21, $\mathrm{P} 28$, and P35, and pups enucleated at P11 were tested at P21. Surprisingly, enucleation at P3 resulted in the development of longer wake bout durations during the day, a pattern opposite to the pattern expressed by sham controls as well as pups enucleated at P11. Based on these results, we suggest that visual system stimulation via the RHT during a sensitive period exerts an organizational influence on the development of circadian sleep-wake activity.

\section{Materials and Methods}

All experiments were performed in accordance with National Institutes of Health guidelines for the care of animals in research and were approved by the Institutional Animal Care and Use Committee of the University of Iowa. All efforts were made to minimize the number of animals used.

\section{Subjects}

A total of 264 Sprague-Dawley rats from 64 litters were used. Males and females were equally represented in all experiments and littermates were always assigned to different experimental groups. Litters were culled to 8 pups within $3 \mathrm{~d}$ of birth (day of birth $=\mathrm{P} 0$ ). Mothers and their litters were housed and raised in standard laboratory cages $(48 \mathrm{~cm}$ long $\times 20 \mathrm{~cm}$ wide $\times 26 \mathrm{~cm}$ high) in the animal colony at the University of Iowa. Food and water were available $a d$ libitum. All animals were maintained on a 12-h light-dark schedule with lights on at $0700 \mathrm{~h}$.

\section{Surgery}

Implantation of nuchal EMG electrodes-In Experiments 1 and 2, under isoflurane anesthesia, two bipolar stainless steel electrodes ( $50 \mu \mathrm{m}$ diameter, California Fine Wire, Grover Beach, CA) were inserted bilaterally into the nuchal muscles and secured with flexible collodion (Seelke et al. 2005). After surgery, pups recovered in a humidified test chamber maintained at thermoneutrality. All pups were tested on the same day that EMG electrodes were implanted. Regardless of whether testing occurred during the day or night, electrode implantation took place at least $1 \mathrm{~h}$ before testing. At night, all surgeries were performed under 
dim red light illumination, with care being taken to ensure that infants were not exposed to white light.

Bilateral enucleation-In Experiment 2, pups were enucleated at two ages: P3 $(n=160)$ and P11 $(n=32)$. For each litter, 4 littermates were enucleated and the remaining 4 received sham surgeries. Under isoflurane anesthesia, each eyelid was opened, the eyeball was removed, and the optic nerve and blood vessels were cauterized. The eyelids were then closed and sealed using Vetbond (3M, St. Paul, Minnesota, United States). The sham surgery was identical up to the point of eyelid opening. Pups recovered in a humidified incubator maintained at thermoneutrality $\left(35^{\circ} \mathrm{C}\right)$ for $3 \mathrm{~h}$. After recovery, all 8 littermates were returned to the home cage and dam until testing.

\section{Apparatus}

P2-3 (hereafter P2) and P8-9 (hereafter P8) subjects were tested in an electrically shielded double-walled glass chamber sealed with a rubber lid (height, $18 \mathrm{~cm}$; i.d., $9 \mathrm{~cm}$ ). P15-16 (hereafter P15), P21-22 (hereafter P21), P28-29 (hereafter P28), and P35-36 (hereafter P35) subjects were tested in a larger chamber (height, $18 \mathrm{~cm}$; i.d., $12 \mathrm{~cm}$ ). Air temperature inside each chamber was controlled by regulating the temperature of the water that passed through its walls. Air temperature was regulated at thermoneutrality for each age (i.e., $\mathrm{P} 2: 35.5^{\circ} \mathrm{C} ; \mathrm{P} 8$ : $35^{\circ} \mathrm{C}$; P15, P21: $32{ }^{\circ} \mathrm{C}$; P28, P35: $29^{\circ} \mathrm{C}$ ). Compressed, humidified air passed through the chamber at the rate of $300 \mathrm{ml} / \mathrm{min}$. A round platform constructed of polyethylene mesh was fitted inside each chamber so that the pup co uld move freely on the platform's surface. The mesh allowed for the movement of air from the bottom of the chamber (where it entered) to the top of the chamber (where it was drawn for analysis of its oxygen content).

Oxygen consumption was measured as described elsewhere (Blumberg and Stolba 1996). Briefly, a two-channel electrochemical oxygen analyzer (Ametek, Pittsburgh, PA) was used to compare the oxygen concentration of the air passing through the chamber with that of the nonrespired air. The difference in percentage oxygen between the chamber's effluent airstream and the nonrespired airstream reflects oxygen consumption by the pup. Specifically, by knowing the air flow rate (i.e., $300 \mathrm{ml} / \mathrm{min}$ ) and the pup's body weight, oxygen consumption can be calculated. All oxygen consumption values are presented as $\mathrm{ml} \mathrm{O}_{2} / 100 \mathrm{~g} / \mathrm{min}$.

Nuchal electrodes were connected to differential amplifiers (A-M systems, Carlsborg, WA) and their signals were amplified (x10k) and filtered (300-5000 Hz). EMG and oxygen consumption data were acquired (1000 samples/s) and stored using a data acquisition system (BioPac Systems, Santa Barbara, CA).

Procedure

Experiment 1: Development of day-night differences in sleep and wakefulness - Seventy-two P2, P8, P15, and P21 male and female rats from 24 litters $(n=6$ at each age $\times$ 4 age groups $\times 3$ test times) were used. Three same-sex littermates were tested successively during the day (hereafter day 1), that night, and the following day (hereafter day 2). Three additional same-sex littermates were tested at one of the 3 other ages. Males and females were equally represented in each age group. Littermates were always assigned to different groups and no more than 6 pups were tested from a given litter.

On day 1, the first of 3 littermates was implanted with nuchal EMG electrodes and acclimated to the test chamber for at least $1 \mathrm{~h}$, at which time collection of EMG and oxygen consumption data began. Data acquisition continued for $2 \mathrm{~h}$ at P2 and P8 from 1200 to $1400 \mathrm{~h}$, for $3 \mathrm{~h}$ at $\mathrm{P} 15$ from 1130 to $1430 \mathrm{~h}$, and for $6 \mathrm{~h}$ at P21 from 1000 to $1600 \mathrm{~h}$. A second littermate was implanted with nuchal EMG electrodes (again, under red light illumination) and tested that 
evening. Tests occurred at P2 and P8 from 2400 to $0200 \mathrm{~h}$, at P15 from 2330 to $0230 \mathrm{~h}$, and at P21 from 2200 to $0400 \mathrm{~h}$. On day 2, the third littermate was tested identically to the subject on day 1. Upon completion of testing, each pup was killed with an overdose of sodium pentobarbital.

Experiment 2: Effects of bilateral enucleation on day-night differences in sleep and wakefulness-One hundred ninety-two male and female rats from 40 litters were used. For subjects receiving enucleation or sham surgery at P3, testing occurred at P8 $(n=32), \mathrm{P} 15$ $(n=32), \mathrm{P} 21(n=32), \mathrm{P} 28(n=32)$, or P35 $(n=32)$. For subjects receiving enucleation or sham surgery at P11, testing occurred only at P21 $(n=32)$. At each age, two littermates (one enucleate and one sham) were tested during the day and two more were tested at night (i.e., $n=8$ subjects per group). Males and females were equally represented in each age group. For those subjects tested at P28 and P35, enucleated and sham littermates were weaned at P21 and housed with same-sex siblings in groups of 4 .

For pups that had surgery on $\mathrm{P} 3$, and on the day of testing at P8, P15, P21, P28, and P35, two same-sex littermates, one enucleated and one sham, were implanted with nuchal EMG electrodes and acclimated in separate test chambers for at least $1 \mathrm{~h}$, at which time data collection began for both pups. Data acquisition continued for $2 \mathrm{~h}$ at P8 from 1200 to $1400 \mathrm{~h}$, and for 6 $\mathrm{h}$ at P15, P21, P28, and P35 from 1000 to $1600 \mathrm{~h}$. At night, two additional same-sex littermates were implanted with EMG electrodes (again, under red light illumination) and tested identically to those during the day. Nighttime tests at P8 occurred from 2400 to $0200 \mathrm{~h}$ and at P15, P21, P28, and P35 from 2200 to $0400 \mathrm{~h}$. The nighttime tests preceded the daytime tests in half of the subjects. The remaining 4 pups in each litter were tested at one of the 2 other ages. Finally, for sham and enucleated pups whose surgery occurred at P11 and were tested at P21, the test procedure was identical.

\section{Data Analysis}

For all subjects, EMG data were analyzed off-line using BioPac Software. The EMG signal was integrated and full-wave rectified, and then dichotomized into periods of high muscle tone and atonia (or wakefulness and sleep, respectively), as described earlier (Karlsson et al. 2004). Data were scored by an experienced individual blind to experimental condition. In Experiment 2, subjects were occasionally excluded from analysis due to poor or incomplete EMG records. In addition, one pup in Experiment 2 was excluded from analysis because its mean sleep duration was greater than 2 standard deviations from the group mean.

Sleep and wake bout durations were imported into Statview 5.0 (SAS Institute, Cary, NC) for analysis. Mean bout durations were determined. Percentage time awake was calculated by dividing the mean wake bout duration by the sum of the mean sleep and wake bout durations, and multiplying by 100 . Mean number of cycles per hour was calculated by summing the total number of sleep and wake bouts, dividing by 2 , and dividing by the length of the test (h). Mean oxygen consumption $\left(\mathrm{ml} \mathrm{O}_{2} / 100 \mathrm{~g} / \mathrm{min}\right.$ ) for each pup was calculated from 5 random 10-s periods during sleep.

In Experiment 1, a two-factor analysis of variance (ANOVA) was used to test for differences across age and time (i.e., day, night). Planned comparisons using paired t tests were used to assess day-night differences within ages. In Experiment 2, overall ANOVAs were performed to test for differences across age (for pups enucleated at P3), groups (i.e., sham, enucleate) and time (i.e., day, night). Planned comparisons using unpaired t tests were used to assess daynight differences within groups. 
Survivor distributions of sleep and wakefulness were produced from each pup and also from pooled data at each age, as described elsewhere (Blumberg et al. 2005). Regression analyses were performed to assess the degree of fit $\left(\mathrm{r}^{2}\right)$ to exponential and power-law distributions.

In addition to log-survivor analyses of pooled wake bout durations, differences between groups were tested by determining, for each P21 subject, the median wake bout duration $\left(\mathrm{T}_{50 \%}\right)$ and the wake bout duration at the $10^{\text {th }}$ percentile $\left(\mathrm{T}_{10 \%}\right)$. Group differences in the means of these values were tested using the Mann-Whitney $U$ test.

For all tests, alpha was set at 0.05 . Means are presented with their standard errors.

\section{Results}

\section{Experiment 1: Development of day-night differences in sleep and wakefulness}

Mean sleep bout durations were significantly lower at night than during the day at $\mathrm{P} 2, \mathrm{P} 8$, and $\mathrm{P} 21$ (Figure 1A). ANOVA revealed significant main effects of age $\left(F_{3,60}=328.8, p<0.0001\right)$ and time $\left(F_{2,60}=18.3, p<0.0001\right)$, but not a significant age $\times$ time interaction $\left(F_{6,60}=2.2\right)$. For mean wake bout durations (Figure 1B), ANOVA revealed a significant main effect of age $\left(F_{3,60}=34.0, p<0.0001\right)$ and an age $\times$ time interaction $\left(F_{6,60}=4.0, p<0.005\right)$, but not a significant effect of time $\left(F_{2,60}=3.0\right)$. Only at P21 were mean wake bout durations significantly different at night than during the day.

For mean percentage of time awake (Figure 1C), ANOVA revealed significant main effects of age $\left(F_{3,60}=15.1, p<0.0001\right)$ and time $\left(F_{2,60}=7.7, p<0.005\right)$, and an age $\times$ time interaction $\left(F_{6,60}=2.4, p<0.005\right)$. At P15 and P21, the mean percentage of time awake was significantly greater at night than during the day.

For mean number of cycles per hour (Figure 1D), ANOVA revealed significant main effects of age $\left(F_{3,60}=221.7, p<0.0001\right)$ and time $\left(F_{2,60}=20.7, p<0.0001\right)$, and an age $\times$ time interaction $\left(F_{6,60}=8.7, p<0.0001\right)$. At $\mathrm{P} 2$ and $\mathrm{P} 8$, the number of cycles per hour was significantly greater at night than during the day.

In general, mean oxygen consumption during sleep was greater at night than during the day at all four ages (Figure 1E). ANOVA revealed main effects of age $\left(F_{3,60}=20.1, p<0.0001\right)$ and time $\left(F_{2,60}=12.5, p<0.0001\right)$, but not a significant age $\times$ time interaction $\left(F_{6,60}=0.7\right)$.

Survivor distributions for pooled sleep and wake bout durations are presented in Figure 2. These plots can be used to track the statistical distributions of bout durations across development, as shown previously (Blumberg et al. 2005). In Figure 2A, the sleep bout durations at each age, and during the day and night, fall along a straight line, indicative of an exponential distribution. The trend across development of increasing sleep bout durations is represented on these plots as a decrease in slope with increasing age. Finally, consistent with Figure 1A, sleep bout durations were shorter at night than during the day, particularly at P8, but also at $\mathrm{P} 2$ and $\mathrm{P} 21$.

As shown in Figure 2B, wake bout durations exhibited pronounced developmental changes in day-night differences and statistical distribution. At P2 and P8, wake bout durations fall along a straight line, again indicative of an exponential distribution; in addition, bout durations were shorter at night than during the day, especially at P2. At P15 and P21 during the day and night, wake bout durations no longer fall along a straight line. Finally, consistent with Figures 1B and $1 \mathrm{C}$, at P15 and even more clearly at P21, wake bout durations were longer at night than during the day, as indicated by the increased percentage of bouts exhibiting longer bout durations. 
We next quantified the fit $\left(\mathrm{r}^{2}\right)$ of each subject's sleep and wake bout durations during the day and night to exponential and power-law distributions. For sleep bout durations, ANOVAs performed separately for day 1 , night, and day 2 revealed significant main effects of age $\left(F_{3,40} \mathrm{~S}>5.5, p \mathrm{~s}<0.005\right)$ and distribution $\left(F_{1,40} \mathrm{~s}>586.2, p \mathrm{~s}<0.0001\right)$, and age $\times$ distribution interactions $\left(F_{3,40} \mathrm{~s}>3.9, p \mathrm{~s}<0.05\right)$. Paired $\mathrm{t}$ tests revealed that sleep bout durations were always better fit by an exponential distribution than by a power-law distribution.

For wake bout durations, ANOVAs performed separately for day 1, night, and day 2 revealed significant main effects of age $\left(F_{3,40} \mathrm{~s}>9.8, p \mathrm{~s}<0.0001\right)$ and distribution $\left(F_{1,40} \mathrm{~s}>30.1, p \mathrm{~s}<\right.$ $0.0001)$, and age $\times$ distribution interactions $\left(F_{3,40} \mathrm{~s}>43.2, p \mathrm{~s}<0.0001\right)$. Paired $\mathrm{t}$ tests revealed that wake bout durations at $\mathrm{P} 2$, regardless of time, were better fit by an exponential distribution than by a power-law distribution, but that this pattern had reversed by P15.

\section{Experiment 2: Effects of bilateral enucleation on day-night differences in sleep and wakefulness}

Of the 96 enucleates, 4 pups died before testing (4.2\%); of the 96 shams, 1 pup died before testing $(1.0 \%)$. In addition, body weights did not differ significantly between enucleates and shams at any age tested. Therefore, we found no evidence that enucleation prevented pups from competing successfully with sham siblings for maternal care or interfered with normal growth.

For mean sleep bout durations and for those subjects that had surgery at P3 (Figure 3; top row), an overall ANOVA revealed a significant age effect $\left(F_{4,124}=5.7, p<0.0005\right)$, and significant group $\times$ time $\left(F_{1,124}=10.8, p<0.005\right)$ and age $\times$ group $\times$ time $\left(F_{4,124}=3.2, p<0.05\right)$ interactions. In contrast, for those subjects that had surgery at P11 and tested at P21, ANOVA did not reveal significant main effects or interactions.

For mean wake bout durations and for those subjects that had surgery at P3 (Figure 3; middle row), an overall ANOVA revealed a significant age effect $\left(F_{4,124}=9.3, p<0.0001\right)$, and significant group $\times$ time $\left(F_{1,124}=24.9, p<0.0001\right)$ and age $\times$ group $\times$ time $\left(F_{4,124}=3.5, p<\right.$ 0.01 ) interactions. In contrast, for those subjects that had surgery at P11 and tested at P21, ANOVA revealed only a significant effect of time $\left(F_{1,24}=14.4, p<0.001\right)$.

The pattern described above for mean wake bout duration was nearly identical for mean percentage of time awake (Figure 3; bottom row). An overall ANOVA revealed a significant age effect $\left(F_{4,124}=4.4, p<0.005\right)$, and significant group $\times$ time $\left(F_{1,124}=36.6, p<0.0001\right)$ and age $\times$ group $\times$ time $\left(F_{4,124}=5.6, p<0.0005\right)$ interactions. Finally, for those subjects that had surgery at P11 and tested at P21, ANOVA again revealed only a significant effect of time $\left(F_{1,24}=20.2, p=0.0001\right)$.

Log-survivor plots of pooled P21 wake bout durations for enucleated and sham subjects, presented in Figure 4, reinforce the results described above. For pups that had surgery at P3 (Figure 4A), wake bout durations were longer at night than during the day for the sham pups, whereas the opposite pattern was found for enucleated pups. For pups that had surgery at P11 (Figure 4B), wake bout durations were longer at night than during the day for both the sham and enucleated pups.

Next, for each subject, we determined the wake bout duration at the $10^{\text {th }}$ percentile $\left(\mathrm{T}_{10 \%}\right)$. The group means of these values are presented in the right panels of Figure 4. For pups that had surgery at P3 (Figure 4A), sham subjects exhibited longer wake bout durations at night $(z=2.6 ; p<0.01)$, whereas enucleated subjects exhibited longer wake bout durations during the day $(z=2.3 ; p<0.05)$. For pups that had surgery at P11 (Figure 4B), both sham $(z=2.1$, $p<0.05)$ and enucleated $(z=2.9, p<0.005)$ subjects exhibited longer wake bout durations at night. Similar results were obtained for values at $\mathrm{T}_{50 \%}$ (i.e., median; data not shown). 
We found no evidence that enucleation at P3 or P11 differentially affected the statistical distributions of sleep or wake bout durations at any age (data not shown).

\section{Discussion}

This study examined the organization of daytime and nighttime sleep-wake activity in in rats across early development. Experiment 1 demonstrated that day-night differences in sleep-wake activity can be detected soon after birth. Specifically, at P2, sleep and wake bout durations were generally shorter at night, and combined to result in approximately $50 \%$ more sleep-wake cycles at night than during the day. Nocturnal wakefulness first emerged around P15 at around the same time as did power-law wake behavior (Blumberg et al. 2005) and became even more pronounced by $\mathrm{P} 21$. It was also at these ages that the number of sleep-wake cycles at night and during the day achieved balance (see Figure 1D), perhaps reflecting reciprocal circadian modulation of the SCN on downstream neural circuitry governing sleep and wakefulness.

Developmental studies in rats have shown that nearly all neurons in the $\mathrm{SCN}$ are formed by embryonic day (E)18 (Ifft 1972) and, by E19, the SCN is more metabolically active during the day than at night and is synchronized to the dam's SCN activity (Reppert and Schwartz 1984). Therefore, it is plausible that SCN circadian activity, entrained to that of the dam, modulates sleep-wake rhythmicity as early as the first postnatal week.

Constraints associated with the provisioning of milk may also play a role in shaping the development of circadian sleep-wake rhythms. The rat dam's milk ejection reflex only occurs during slow-wave sleep (Lincoln 1983, Voloschin and Tramezzani 1979). Consequently, pups suckle more, receive more milk, and gain more weight during the day than at night (Levin and Stern 1975, Thiels et al. 1990). The transition to a nocturnal feeding pattern appears to occur soon after weaning and the transition to solid food (Levin and Stern 1975).

In Experiment 2, enucleation at P3 or P11 did not prevent the development of day-night differences in sleep-wake activity or power-law wake behavior. However, enucleation at P3 did result in P21 rats that exhibited longer wake bout durations during the day. Critically, because this pattern was sustained at P28 and P35, it is unlikely that these enucleated subjects were free-running. In contrast, enucleation at P11 resulted in P21 rats that exhibited longer wake bout durations at night, similar to shams (although it should be noted that testing these subjects only at P21 makes it more difficult to be confident that they were not free-running). These results suggest that enucleated infant rats differentially entrain to social zeitgebers within the nest environment and colony room depending on when the enucleation takes place (Mistlberger and Skene 2004). Indeed, in pups blinded at birth and tested beyond the first postnatal week, nursing mothers set the phase of circadian SCN activity (Ohta et al. 2002), pineal serotonin N-acetyltransferase activity and corticosterone levels (Takahashi and Deguchi 1983), and drinking (Shimoda et al. 1986) and locomotor (Honma et al. 1987) activity.

Because the SCN is more metabolically active during the day than at night in both diurnal and nocturnal species (Smale et al. 2003), we do not expect that enucleation in early infancy alters the circadian timing of SCN metabolic activity. Rather, we hypothesize that visual system stimulation — from light and/or spontaneous activity within the retina — transmitted through the RHT to the SCN, induces functional changes in SCN interactions with its downstream neural structures.

In support of this hypothesis, we note that in non-enucleated rats, the shift from maternal to photic entrainment depends upon the development of functional connectivity between the RHT and SCN, which occurs between P0 and P12 (Duncan et al. 1986, Hannibal and Fahrenkrug 2004, Speh and Moore 1993). Moreover, in adults, light may act as a zeitgeber by up-regulating growth factors (e.g., NGF1-A, BDNF) in the SCN (Allen and Earnest 2005, Liang et al. 
2000, Tanaka et al. 1999). Such up-regulation of gene activity — seen during everyday entrainment in adults - could also, we suggest, play an inductive, organizational role during a sensitive period when the RHT is establishing its connections with the SCN. Interestingly, it was recently suggested that photoperiodic conditions during the perinatal period in hamsters can organize the adult immune system (Weil et al. 2006).

Future research should address more thoroughly the effects of early blindness on the expression of circadian sleep-wake rhythms and locomotor activity in adults. In addition, it will be important to examine the mechanisms mediating the developmental effects of enucleation on SCN functionality. For example, if, as hypothesized here, photic stimulation via the RHT induces organizational changes in the connectivity of the efferent connections from the SCN, then those changes should be detectable as altered anatomical and physiological connections between the SCN and its target nuclei (Schwartz et al. 2004). If this hypothesis is supported by subsequent research, it would suggest one mechanism by which species differences in nocturnality and diurnality have evolved (Smale et al. 2003).

\section{Acknowledgments}

This work was supported by a research grant (MH50701) and an Independent Scientist Award (MH66424) from the National Institute of Mental Health (to M.S.B.). The second and third authors contributed equally to this project.

\section{References}

Allen GC, Earnest DJ. Overlap in the distribution of TrkB immunoreactivity and retinohypothalamic tract innervation of the rat suprachiasmatic nucleus. Neurosci Lett 2005;376:200-204. [PubMed: 15721221]

Blumberg MS, Seelke AM, Lowen SB, Karlsson KA. Dynamics of sleep-wake cyclicity in developing rats. Proc Natl Acad Sci U S A 2005;102:14860-14864. [PubMed: 16192355]

Blumberg MS, Stolba MA. Thermogenesis, myoclonic twitching, and ultrasonic vocalization in neonatal rats during moderate and extreme cold exposure. Behav Neurosci 1996;110:305-314. [PubMed: 8731057]

Duncan MJ, Banister MJ, Reppert SM. Developmental appearance of light-dark entrainment in the rat. Brain Res 1986;369:326-330. [PubMed: 3697748]

Ellison N, Weller JL, Klein DC. Development of a circadian rhythm in the activity of pineal serotonin N-acetyltransferase. J Neurochem 1972;19:1335-1341. [PubMed: 5025129]

Frank MG, Heller HC. Development of diurnal organization of EEG slow-wave activity and slow-wave sleep in the rat. Am J Physiol 1997;273:R472-R478. [PubMed: 9277528]

Fuller PM, Gooley JJ, Saper CB. Neurobiology of the sleep-wake cycle: sleep architecture, circadian regulation, and regulatory feedback. J Biol Rhythms 2006;21:482-493. [PubMed: 17107938]

Gramsbergen A. The development of the EEG in the rat. Dev Psychobiol 1976;9:501-515. [PubMed: 1001836]

Hannibal J, Fahrenkrug J. Melanopsin containing retinal ganglion cells are light responsive from birth. Neuroreport 2004;15:2317-2320. [PubMed: 15640747]

Henning SJ, Gisel EG. Nocturnal feeding behavior in the neonatal rat. Physiol Behav 1980;25:603-605. [PubMed: 7208657]

Honma K, Honma S, Shirakawa T, Hiroshige T. Phase setting of circadian locomotor rhythm of infant rats. Am J Physiol 1987;252:R256-261. [PubMed: 3812764]

Ifft JD. An autoradiographic study of the time of final division of neurons in rat hypothalamic nuclei. J Comp Neurol 1972;144:193-204. [PubMed: 5029133]

Karlsson KA, Blumberg MS. Active medullary control of atonia in week-old rats. Neuroscience 2005;130:275-283. [PubMed: 15561443]

Karlsson KA, Kreider JC, Blumberg MS. Hypothalamic contribution to sleep-wake cycle development. Neuroscience 2004;123:575-582. [PubMed: 14698764] 
Kittrell EMW, Satinoff E. Development of the circadian rhythm of body temperature in rats. Physiol Behav 1986;38:99-104. [PubMed: 3786507]

Levin R, Stern JM. Maternal influences on ontogeny of suckling and feeding rhythms in the rat. J Comp Physiol Psychol 1975;89:711-721. [PubMed: 1236874]

Liang FQ, Allen G, Earnest D. Role of brain-derived neurotrophic factor in the circadian regulation of the suprachiasmatic pacemaker by light. J Neurosci 2000;20:2978-2987. [PubMed: 10751450]

Lincoln, DW. Physiological mechanisms governing the transfer of milk from mother to young. In: Rosenblum, LA.; Moltz, H., editors. Symbiosis in parent-offspring interactions. Plenum Press; New York: 1983. p. 77-112.

Mistlberger RE, Skene DJ. Social influences on mammalian circadian rhythms: animal and human studies. Biol Rev Camb Philos Soc 2004;79:533-556. [PubMed: 15366762]

Moore RY. Organization and function of a central nervous system circadian oscillator: the suprachiasmatic hypothalamic nucleus. Fed Proc 1983;42:2783-2789. [PubMed: 6135628]

Nuesslein-Hildesheim B, Imai-Matsumura K, Doring H, Schmidt I. Pronounced juvenile circadian core temperature rhythms exist in several strains of rats but not in rabbits. J Comp Physiol B 1995;165:1317. [PubMed: 7601955]

Ohta H, Honma S, Abe H, Honma K. Effects of nursing mothers on rPer1 and rPer2 circadian expressions in the neonatal rat suprachiasmatic nuclei vary with developmental stage. Eur J Neurosci 2002;15:1953-1960. [PubMed: 12099901]

Reppert SM, Schwartz WJ. The suprachiasmatic nuclei of the fetal rat: characterization of a functional circadian clock using 14C-labeled deoxyglucose. J Neurosci 1984;4:1677-1682. [PubMed: 6737036]

Reppert SM, Weaver DR, Rivkees SA. Maternal communication of circadian phase to the developing mammal. Psychoneuroendocrinology 1988;13:63-78. [PubMed: 3287418]

Rusak B, Zucker I. Neural regulation of circadian rhythms. Physiol Rev 1979;59:449-526. [PubMed: 379886]

Schwartz MD, Nunez AA, Smale L. Differences in the suprachiasmatic nucleus and lower subparaventricular zone of diurnal and nocturnal rodents. Neuroscience 2004;127:13-23. [PubMed: 15219664]

Seelke AM, Karlsson KA, Gall AJ, Blumberg MS. Extraocular muscle activity, rapid eye movements and the development of active and quiet sleep. Eur J Neurosci 2005;22:911-920. [PubMed: 16115214]

Sekaran S, Lupi D, Jones SL, Sheely CJ, Hattar S, Yau KW, Lucas RJ, Foster RG, Hankins MW. Melanopsin-dependent photoreception provides earliest light detection in the mammalian retina. Curr Biol 2005;15:1099-1107. [PubMed: 15964274]

Shimoda K, Hanada K, Yamada N, Takahashi K, Takahashi S. Periodic exposure to mother is potent zeitgeber of rat pups' rhythm. Physiol Behav 1986;36:723-730. [PubMed: 3714847]

Smale L, Lee T, Nunez AA. Mammalian diurnality: some facts and gaps. J Biol Rhythms 2003;18:356366. [PubMed: 14582852]

Speh JC, Moore RY. Retinohypothalamic tract development in the hamster and rat. Brain Res Dev Brain Res 1993;76:171-181.

Spiers DE. Nocturnal shifts in thermal and metabolic responses of the immature rat. J Appl Physiol 1988;64:2119-2124. [PubMed: 3391910]

Takahashi K, Deguchi T. Entrainment of the circadian rhythms of blinded infant rats by nursing mothers. Physiol Behav 1983;31:373-378. [PubMed: 6635007]

Tanaka M, Iijima N, Amaya F, Tamada Y, Ibata Y. NGFI-A gene expression induced in the rat suprachiasmatic nucleus by photic stimulation: spread into hypothalamic periventricular somatostatin neurons and GABA receptor involvement. Eur J Neurosci 1999;11:3178-3184. [PubMed: 10510181]

Thiels E, Alberts JR, Cramer CP. Weaning in rats: II. Pup behavior patterns. Dev Psychobiol 1990;23:495-510. [PubMed: 2272406]

Voloschin LM, Tramezzani JH. Milk ejection reflex linked to slow wave sleep in nursing rats. Endocrinology 1979;105:1202-1207. [PubMed: 488006] 
Weil ZM, Pyter LM, Martin LB 2nd, Nelson RJ. Perinatal photoperiod organizes adult immune responses in Siberian hamsters (Phodopus sungorus). Am J Physiol Regul Integr Comp Physiol 2006;290:R1714-1719. [PubMed: 16410397] 


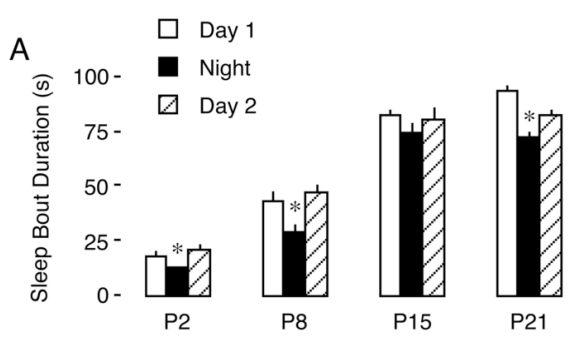

$\mathrm{B}$

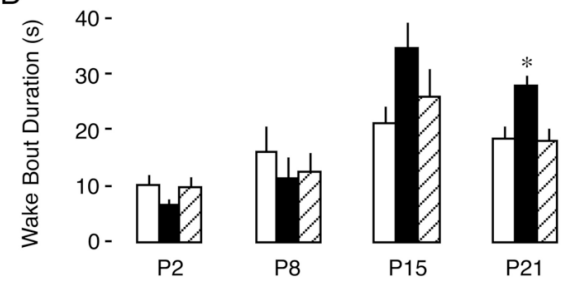

C

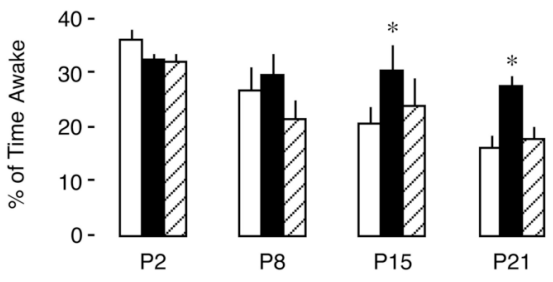

D

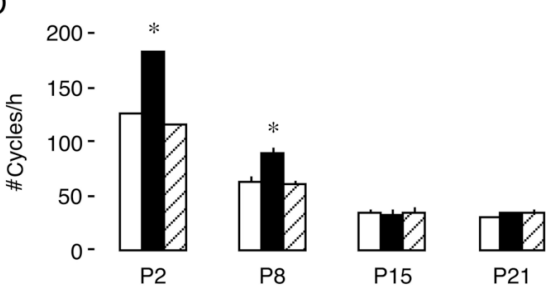

E

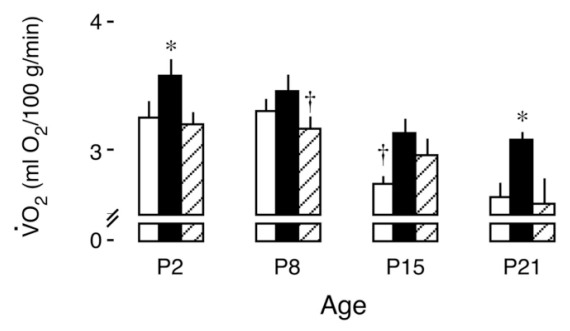

Figure 1. Day-night differences in sleep, wake, and metabolic parameters in infant rats Mean sleep (A) and wake (B) bout durations during the day and night in P2, P8, P15 and P21 rats. (C) Mean percentage of time spent awake at each age. (D) Mean number of sleep-wake cycles per hour. (E) Mean oxygen consumption determined during periods of sleep. * Night value is significantly different from both day 1 and day 2 . $\dagger$ Day 1 or day 2 value is significantly different from night. $n=6$ subjects per group. Means + SE. 


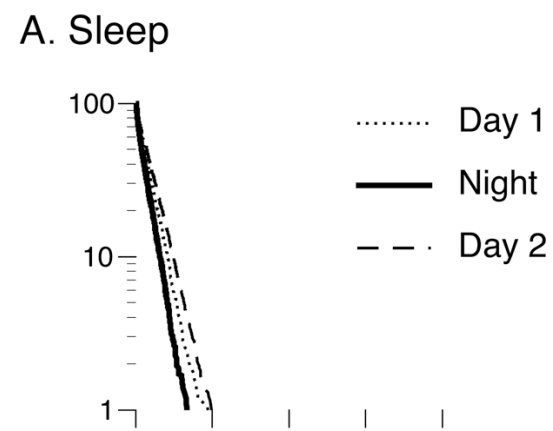

\section{B. Wake}
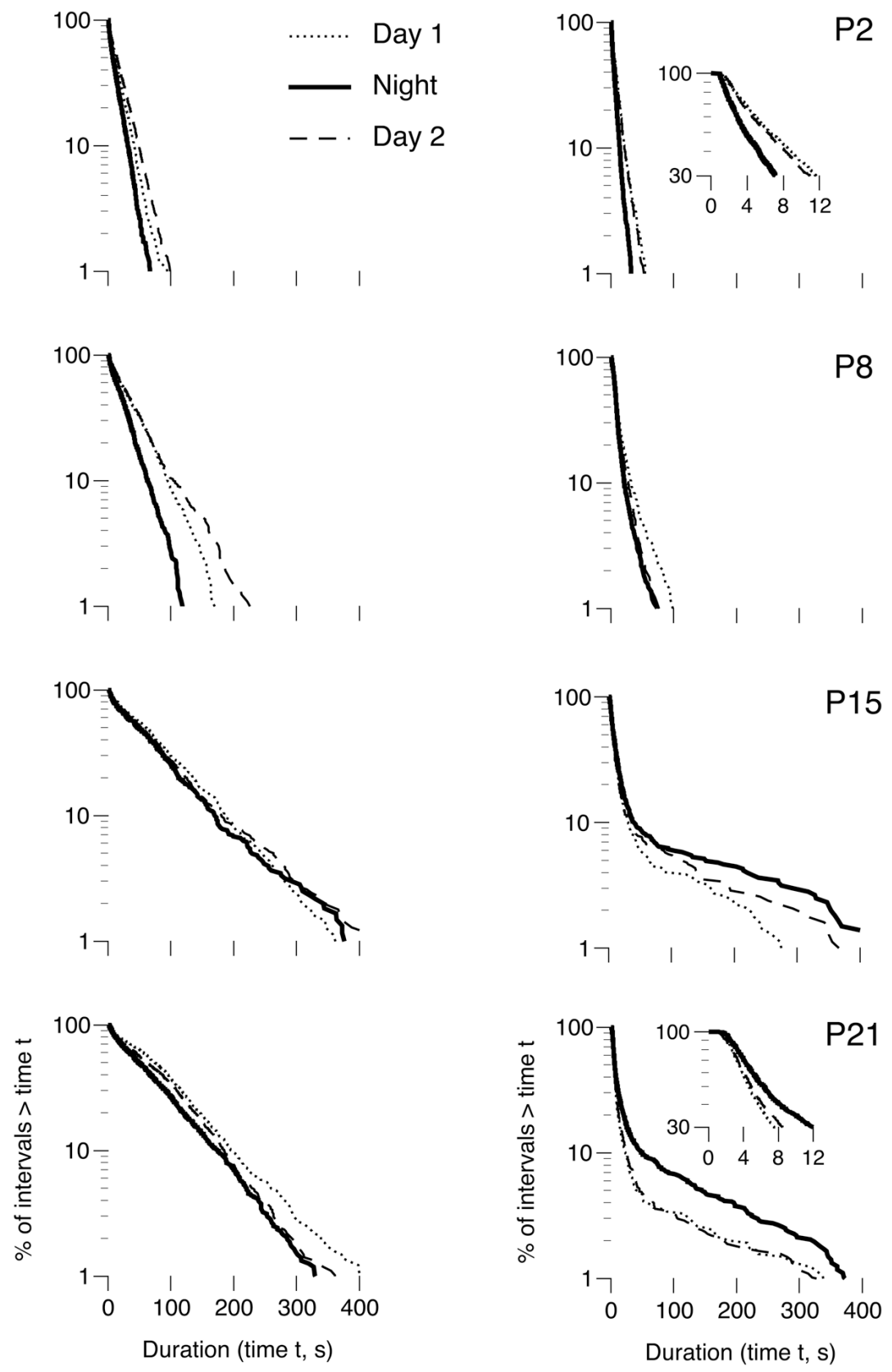

Figure 2. Log-survivor distributions of sleep and wake bout durations

Log-survivor plots of (A) sleep and (B) wake bout durations for rats at P2, P8, P15 and P21 on day 1 (dotted line), at night (solid line), and on day 2 (dashed line). Each plot is constructed from pooled data (620-2213 points per plot). Straight lines on these semi-log plots indicate that the data follow an exponential distribution. Insets provide magnified views at shorter bout durations. 


\section{A. Sham}
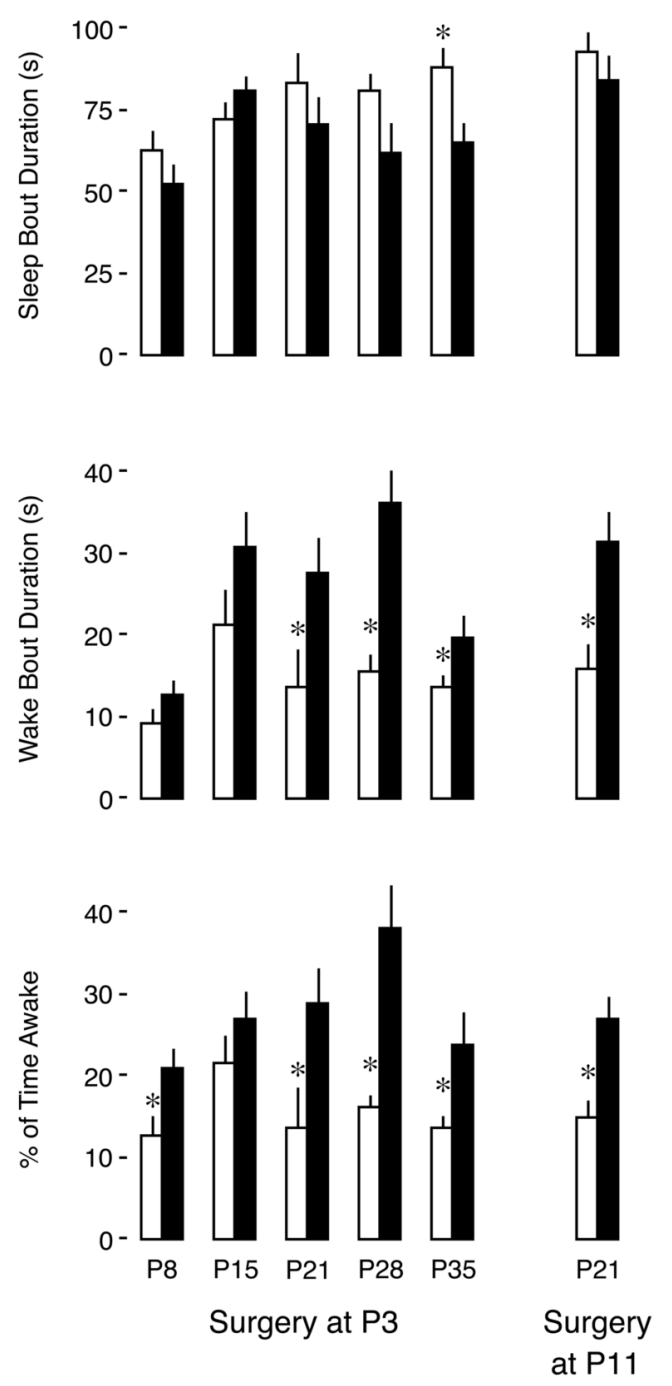

B. Enucleate

Day
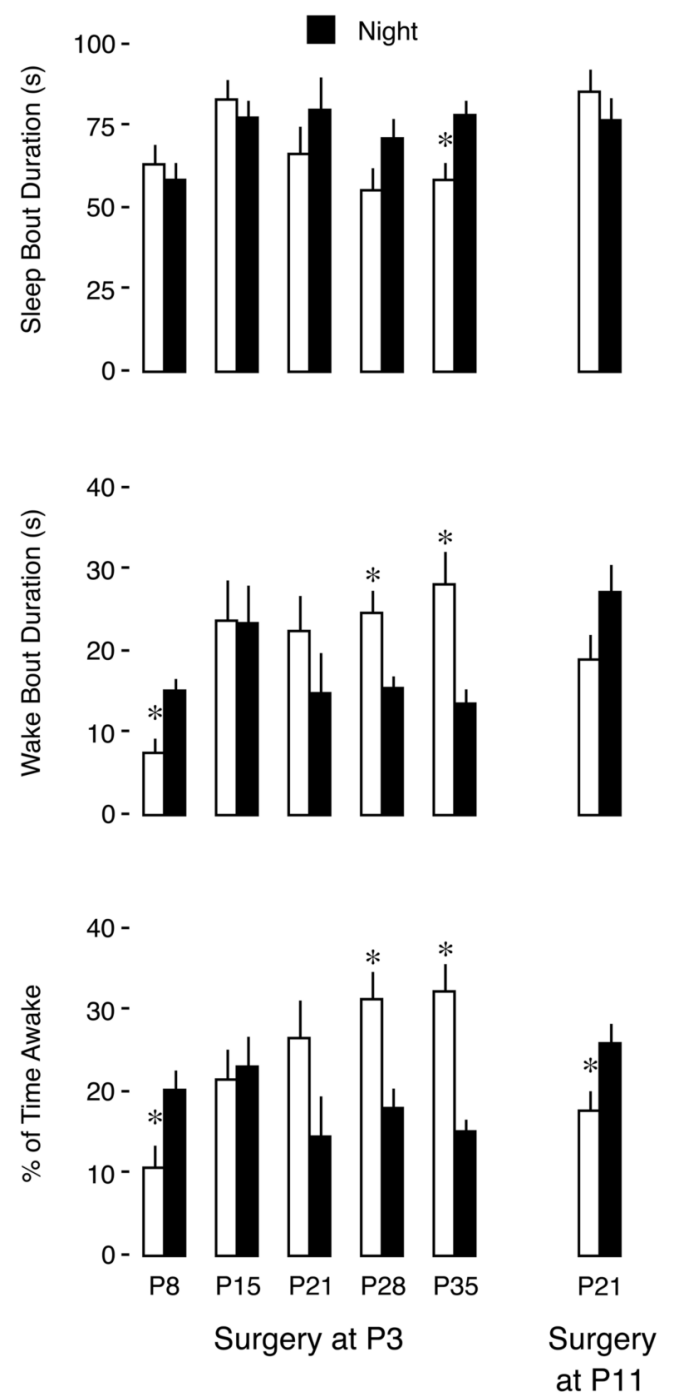

Figure 3. Day-night differences in wake parameters in sham and enucleated infant rats Mean sleep bout durations (top row), wake bout durations (middle row), and percentage of time awake (bottom row) during the day and night in P8, P15, P21, P28, and P35 rats after sham surgery (A) or bilateral enucleation (B) at P3. Also shown are data from P21 rats after sham or enucleation surgery at P11. * Significantly different from corresponding nighttime value. $n=6-8$ subjects per group. Means + SE. 


\section{A. Surgery at P3}

Sham

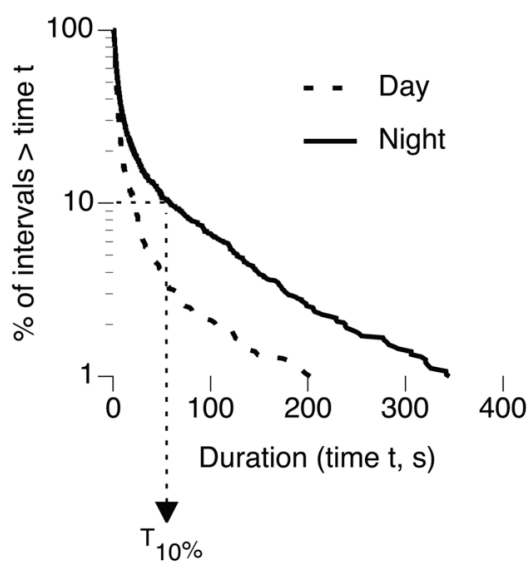

B. Surgery at $\mathrm{P} 11$
Sham

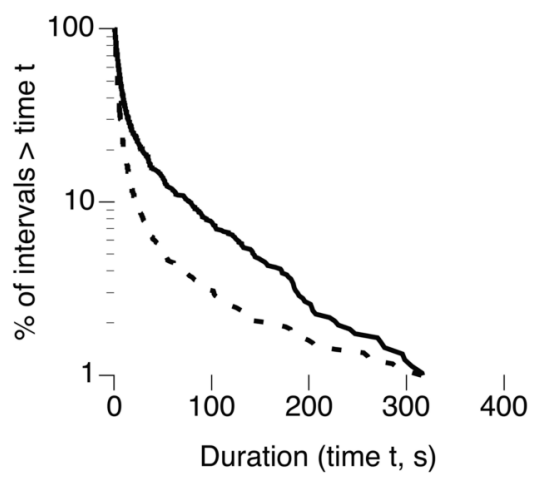

\section{Enucleated}
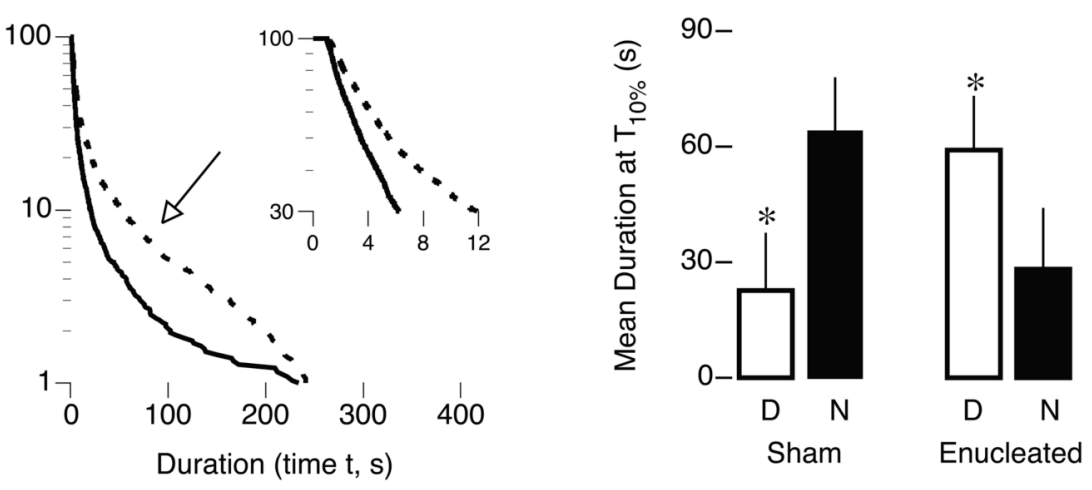

Figure 4. Effects of enucleation at P3 or P11 on wake bout durations during the day and night in P21 rats

(A) Log-survivor plots of pooled wake bout durations for P21 subjects that experienced sham surgery or enucleation on P3 (1339-1976 points per plot). Pups were tested during the day (dotted line) or at night (solid line). Open arrow indicates group exhibiting longer wake bout durations during the day. $\mathrm{T}_{10 \%}$ is indicated in the far-left plot to illustrate how this value was derived. Insets provide magnified views to reveal consistency of day-night differences in enucleated subjects even at short bout durations. The right panel presents mean values of $\mathrm{T}_{10 \%}$ across individual subjects. (B) Same as in (A) except pups experienced enucleation or sham surgery on P11 (897-1409 points per log-survivor plot). * Significantly different from the corresponding nighttime value. Means + SE. 